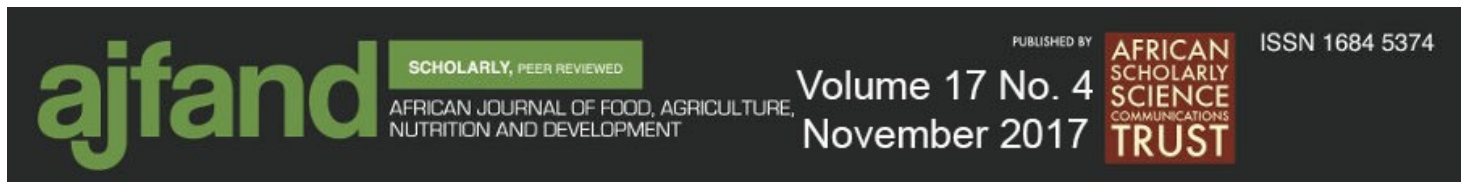

\title{
RED PALM OIL BEAN-STEW IMPROVED SERUM VITAMIN A AND HAEMOGLOBIN CONCENTRATIONS AND ANTHROPOMETRIC INDICATORS OF SCHOOL CHILDREN WITH LOW VITAMIN A CONCENTRATIONS IN A MALARIA-ENDEMIC SETTING
}

$$
\text { Egbi G }^{1^{*}} \text {, Alatiah } \text { GA }^{2} \text {, Ayi I }{ }^{1} \text { and M Steiner-Asiedu }{ }^{2}
$$

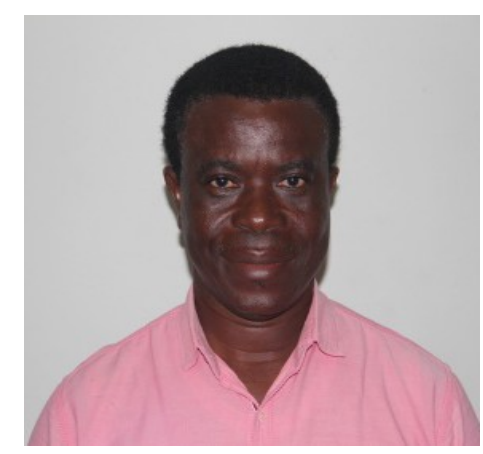

Egbi Godfred

*Corresponding author email: gegbi@noguchi.ug.edu.gh

${ }^{1}$ Noguchi Memorial Institute for Medical Research, College of Health Sciences, University of Ghana, P.O. Box LG 581, Legon, Accra, Ghana

${ }^{2}$ Department of Nutrition and Food Science, College of Applied and Basic Sciences, University of Ghana, P.O. Box LG 134, Legon, Accra, Ghana 


\section{ABSTRACT}

Vitamin A deficiency (VAD), anaemia, and parasitic infections are among the major nutritional and health problems confronting Ghanaian school children. This study assessed the impact of red palm oil bean-stew consumption on serum retinol and haemoglobin concentrations of Ghanaian school children in a malaria-endemic setting. The design was a pre-post nutrition intervention study. It involved 142 6-12 year-old children. Participants were selected by simple random sampling. After baseline sample and data collection, the participants consumed red palm oil bean-stew with gari (made from fermented, grated cassava flour), three times a week for a period of six months. Final biological samples and data were collected as at baseline. Dietary data were collected using Food Frequency Questionnaires and the 24-hour recall procedure. Serum retinol was measured with High Performance Liquid Chromatography and haemoglobin by Haemocue Haemoglobinometer. Malaria parasitaemia and hookworms were examined by microscopy from blood films and stool samples using the Giemsastaining and Kato-Katz techniques, respectively. Data were analysed with Statistical Package for Social Sciences version-23. Mean values for outcome variables were compared between baseline and final using paired t-tests. Results indicated that majority of the participants $(82.4 \%)$ consumed cereals. Many of them also (98.6\%) never consumed dairy or dairy products. Mean serum retinol concentration was $12.1 \pm$ $6.6 \mu \mathrm{g} / \mathrm{dl}$ during baseline and $16.2 \pm 6.4 \mu \mathrm{g} / \mathrm{dl}$ at final, the difference significant at $\mathrm{p}<0.05$. The mean haemoglobin concentration at baseline was $119.4 \pm 10.6 \mathrm{~g} / \mathrm{l}$ and $126.0 \pm 9.34 \mathrm{~g} / 1$ at final, with a significant difference at $\mathrm{p}<0.05$. The prevalence of VAD defined as serum retinol concentration $<20 \mu \mathrm{g} / \mathrm{dl}$ was $76.2 \%$ at the end of the study being significantly different from that at baseline $(93.6 \%), p<0.05$. Prevalence of anaemia was $30.3 \%$ and $11.3 \%$ at baseline and final, respectively with a significant difference at $\mathrm{p}<0.05$. Malaria parasitaemia was prevalent: $67.6 \%$ at baseline and $62.7 \%$ at the end of the study. Only one participant $(0.01 \%)$ was found with hookworm infestation. For participants with VAD, $48.3 \%$ and $36.2 \%$ improved to moderate and normal vitamin A status, respectively at the end of the study. The prevalence of anaemia among VAD participants was $36.2 \%$ at baseline and $12.1 \%$ at final. In conclusion, red palm oil beanstew consumption increased the haemoglobin concentration and minimized prevalence of anaemia among the study participants. It also increased serum retinol concentrations and minimized the prevalence of vitamin A deficiency (especially severe vitamin A deficiency) among the study participants.

Key words: Red palm oil, Vitamin A, Haemoglobin, School children, Malaria, Parasitaemia 


\section{BACKGROUND}

Sound nutrition is critical for good health, growth, development and academic performance of school children, hence inadequate dietary intake of macro- and micronutrients and presence of parasitic infections may result in under nutrition and micronutrient deficiencies with adverse consequences. Micronutrient malnutrition (hidden hunger) remains a key public health challenge for individuals, households, governments, non-governmental organisations and the international community [1]. Vitamin A deficiency (VAD) is endemic among children in many low income countries, especially in sub-Saharan Africa [2]. The critical role vitamin A plays in proper immune function, academic achievements and physical ability of children makes its deficiency a public concern among school children. Vitamin A deficiency may contribute to anaemia through its effects on iron metabolism, haematopoiesis, and increased susceptibility to infections [3].

Gamble et al. [4] found severe VAD to be associated with anaemia among preschool children. It is likely that severe VAD is a risk factor for anaemia and its deficiency might have contributed to the pathogenesis of anaemia among these cohorts of children. School children are the most affected by VAD [5], anaemia [6], and parasitic infections [7] worldwide. Vitamin A deficiency [8,9], anaemia, under nutrition, and parasitic infections [10-12] are the major nutritional and health problems of public health interest confronting Ghanaian school children. Nutritional status is a critical index of quality of life [13]. It directly reflects the socioeconomic status of families, social wellbeing of communities, efficiency of available healthcare systems and their influence on surrounding environments [13]. Adequate nutrition is essential for human capital development as under nourished children attain lower educational achievements [14]. Positive economic outcomes of good nutrition are necessary prerequisites for economic development [15, $16]$.

Malnutrition and diseases mutually reinforce one another and so it is important to examine children for infectious diseases during any nutrition intervention activity. The Ghana school feeding program (GSFP) initiated in 2005 is to provide school children with at least one third of their daily nutrient requirements. Dietary diversification (making use of locally available and accessible foods) could be a vital tool for sustaining the GSFP in order to improve the nutritional status of Ghanaian school children.

There are several nutritional applications for red palm oil (RPO) in the food industry [17]. It contains 15 times the carotenes found in an equal weight of carrot and 44 times those found in green leafy vegetables [18]. According to the Malaysian Palm Oil Council [19], one teaspoon ( $6 \mathrm{~g}$ ) of RPO can provide the RDA (350-400 RE) of vitamin A for children. Thus, two teaspoons of RPO will provide the RDA ( $800 \mathrm{RE})$ for adults. Consumption of RPO is known to increase high-density lipoprotein (HDL) cholesterol and decrease lowdensity lipoprotein (LDL) cholesterol and triglycerides; the overall effect being improved cardiovascular health [20]. Cowpea is a nutritious legume with adequate levels of protein 
and iron [21-23] and serves as a common household food staple in Ghana [24], Benin [23], Nigeria [25, 26], and other developing countries [21]. Cowpea is reported to have cholesterol lowering effects in humans [27]. This ability of cowpea may offset any hypercholesterolemic effects that may be posed by RPO consumption. Limited studies established or evaluated the impact of school feeding programs on the nutritional status and good health of Ghanaian school children. Red palm oil bean-stew is nutritious and is being promoted in the GSFP. This study, therefore, sought to assess the impact of RPO bean-stew on serum retinol and haemoglobin concentrations and anthropometric status of Ghanaian school children in a malaria endemic area.

\section{METHODOLOGY}

\section{Study design}

The study was a one-group longitudinal pre- and post- intervention test design carried out for six months. It was in three phases. Phase-1 was a survey to collect information on socio-demographics and vitamin A rich foods in the community. Phase- 2 was assessment of the chemical composition of the intervention diet. Phase- 3 was the intervention stage where data were collected at pre- and post-intervention. The study involved 6 to 12 year old school children who were not severely anaemic, not allergic to cowpea-based foods or RPO and not on any iron or vitamin A supplements.

\section{Study setting}

The study was conducted in Kodzobi in Adaklu-Anyigbe District, a rural, malaria endemic and crop farming area. The vegetation is mainly savannah, with patches of forest. Information gathered through focus group engagement and participatory appraisal showed that many of the inhabitants were subsistence farmers engaged in cowpea, maize, groundnut and cassavacultivation.

\section{Sample size determination and sampling}

The number of participants randomly selected for the study was 150 based on a confidence level of $95 \%, 80 \%$ statistical power assuming the prevalence of vitamin A deficiency to be $70 \%$ and considering $10 \%$ attrition. Prior to and during the study, all children who reported (backed by oral consent from their parents) to be allergic to beans, palm oil or gari were excluded from the study. Also those found to be on vitamin A, iron or any other dietary supplement were excluded from the study. A total of 145 children at baseline provided blood and stool samples for laboratory analysis and enrolled for the intervention study. There were three dropouts so 142 participants completed the intervention study and provided biological samples. All analyses were based on the data available for these 142 studyparticipants.

\section{Chemical composition of the intervention diet}

Chemical analysis by standard AOAC methods [28] showed the diet as eaten contained moisture $(69.9 \%)$, protein $(20.3 \mathrm{~g})$, fat $(4.4 \mathrm{~g})$, carbohydrate $(73.4 \mathrm{~g})$, ash $(1.4 \mathrm{~g})$ and iron $(4.1 \mathrm{mg})$ per $100 \mathrm{~g}$. A modified version of the HarvestPlus method for extraction of carotene [29] and the scheme for quantification of leafy vegetable carotenoids [30] were 


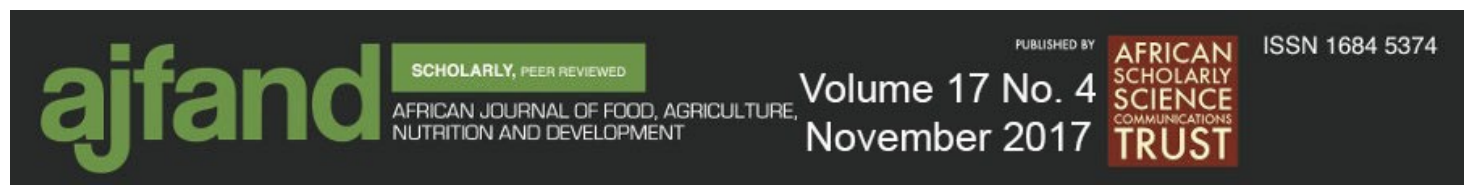

used for determination of beta-carotene content of the intervention diet. Five grams of the diet was soaked with $25 \mathrm{ml}$ of cold acetone in a mortar for 20 minutes. Celite $(1.0 \mathrm{~g})$ and pyrogallol $(0.5 \mathrm{~g})$ were added, and the mixture macerated gently with a pestle and filtered by vacuum through a Buchner funnel containing ash- free filter paper. The maceration and vacuum filtration were repeated until the residue turned colourless. After portioning in petroleum ether, the carotenoid solution was collected into a $200 \mathrm{ml}$ volumetric flask and saponified with an equal volume of $15 \%$ methanolic potassium hydroxide overnight at ambient temperature. The saponified carotenoid solution was poured into a separator funnel and washed several times with distilled water, discarding the lower heavier aqueous solution. The diet contained $645 \mu \mathrm{g}$ beta-carotene $/ 100 \mathrm{~g}$ determined by the High Performance Liquid Chromatography (HPLC) method of HarvestPlus [30].

\section{Intervention phase}

Each participant was given 280 - 300g of RPO bean-stew composed of boiled cowpea, RPO, tomato-pepper sauce and gari (fine grains of grated, fermented, and roasted cassava) at lunch break. They were fed three times a week for a period of six months. At any given instance that a participant was unable to finish his or her serving, the leftover was weighed and subtracted from the total amount of food served to get the actual amount he or she consumed. The meal was to provide at least a third of the daily nutrient requirements.

\section{Data collection}

With the exception of background, anthropometric, and dietary data, samples for serum vitamin A, haemoglobin determination, and parasitological examinations were collected before and at the end of the intervention. Five milliliters of fasting venous blood were collected from each study participant, centrifuged, and serum aliquots were prepared in Eppendorf tubes and stored frozen below $-80^{\circ} \mathrm{C}$ until analysed for vitamin A. Blood samples were also collected and used immediately in the field to determine haemoglobin concentrations. Thick and thin blood smears were prepared on microscope glass slides, allowed to dry in a dust-free area and transported to the laboratory in slide boxes for processing and detection of malaria parasitaemia. Fresh stool samples $(2-3 \mathrm{~g})$ were collected from each study participant in the morning before breakfast by a qualified parasitologist and transported on ice to the laboratory for processing and microscopic examination forhelminthes.

\section{Background data}

A pretested semi-structured questionnaire was used to collect data on participants' demographic characteristics such as gender and age, socio-economic characteristics on parents and guardians, and households; including, occupation, monthly income, marital status, and National Health Insurance Scheme membership status.

A pretested semi-structured questionnaire was used to solicit information on participant's characteristics such as gender, sex, and age. Data collected on household characteristics included mother's and father's age, occupation, education, income, marital status, family size, National Health Insurance Scheme membership and number 
of children. The socio-demographic characteristic data collected included toilet facilities, sources of water, health, banking, market, security, postal and communication facilities.

\section{Anthropometric assessment}

Height and weight of each child, wearing only school attire and no shoes, were measured using a standardized stadiometer (Model HM200P Charder USA) and weighing scale (Model QIE-2003A; EMC China), respectively. Height and weight were measured in triplicates, to the nearest $0.1 \mathrm{~cm}$ and $0.1 \mathrm{~kg}$, respectively. Average weight of school attires were subtracted from each mean weight measurement as correction factors. The average of triplicate measurements was used in calculating the body mass index (BMI) as weight in kilograms divided by height in meters squared $\left(\mathrm{kg} / \mathrm{m}^{2}\right)$ as recommended by the World Health Organization (WHO) [31].

\section{Dietary assessment}

Standard Food Frequency Questionnaire of Noguchi Memorial Institute for Medical Research (NMIMR) Nutrition Department was used in face-to-face interviews to assess the frequency of consumption of various food groups, especially in cowpea-based foods and carotenoid-rich foods by the participants on weekly basis. Diets consumed by the participants belonging to the various food groups, namely: cereals, legumes, roots, tubers, nuts, meat, fish, poultry products, milk products, oils and fats were recorded. The number of times a diet was consumed by a participant was also recorded. Pictures of the various food groups were provided to the study participants for easy recall. Handy kitchen measures (serving as memory aids) such as a set of measuring cups, spoons, ladles and household utensils were provided to assist the respondents in estimating portion sizes of the food items consumed. Before the recall, market and household surveys were conducted to identify commonly used utensils and measures with their corresponding volumes. Also, 24-hour dietary recall procedures were used to collect data on nutrient intakes of the participants on two week days and one day on a weekend. Children between six and eight years of age were interviewed along with their caregivers. To estimate the actual amount of foods consumed by the children, representative food samples were purchased and weighed with sensitive electronic scales (Soehnle 56377 Nasau/Germany, www.soehnle.com) capable of measuring up to 10,000grams. Chemical analyses were done on samples of leafy vegetables by the standard AOAC methods [28]. The analyses showed that the diet contained moisture $(69.9 \%)$, protein $(20.3 \mathrm{~g})$, fat $(4.4 \mathrm{~g})$, carbohydrate $(73.4 \mathrm{~g})$, ash $(1.4 \mathrm{~g})$ and iron $(4.1 \mathrm{mg})$ per $100 \mathrm{~g}$ of the diet as was eaten.

\section{Biochemical assessment}

Haemoglobin concentrations were measured directly in the field from finger-prick blood samples from each participant with the Hemocue Haemoglobinometer (Hemocue AB, Angelhom, Sweden) by strictly following the manufacturer's instructions. Haemoglobin measurement for each participant was in triplicate and the mean haemoglobin concentration was recorded.

Serum vitamin A was measured using a modified version of NMIMR vitamin A determination protocol [32]. Frozen serum samples of the study participants were 
completely thawed for 60 seconds. For each participant, duplicate aliquots of $120 \mu 1$ serum were pipetted and $120 \mu \mathrm{l}$ of methanol added. The mixture was vortexed for 30 seconds to denature protein substances. Five hundred microliters of hexane was added and the resultant mixture vortexed for 120 seconds to solubilize all the fat-soluble components. Two hundred and fifty microliters of supernatant was evaporated slowly and carefully under nitrogen gas to dryness and the residue reconstituted with $120 \mu 1$ of methanol by mixing with a vortex for 15 seconds. One milligram of retinol standard (vitamin A from Sigma Aldrich) in ethanol with $0.1 \%(\mathrm{w} / \mathrm{v})$ BHT was dissolved in $1 \mathrm{ml}$ methanol. Six serial dilutions were made from the $1 \mathrm{mg} / \mathrm{ml}$ stock with $500 \mu 1$ of methanol. One hundred and twenty microliters of each serial dilution of the reference vitamin A standard was injected into the HPLC system. The resultant peaks were plotted against their respective concentrations to establish a standard calibration curve. The chromatogram recorder was programmed to record the peak area, width, height retention time and concentration of retinol in each serum sample. The reconstituted solution was injected into an HPLC system to determine the vitamin A concentration of each participant's sample. Every day of analysis, $120 \mu 1$ of an aliquot of standard retinol was injected into the HPLC system as a control check before running of serum samples. The operation wavelength was $350 \mathrm{~nm}$ at a flow rate of $1 \mathrm{ml}$ per minute. The retention time was 6 minutes.

\section{Parasitological examinations}

Thick and thin blood smears of each participant were Giemsa-stained and examined Microscopically for the presence or the absence of Plasmodium spp. Stool samples were processed using the Kato-Katz technique and examined microscopically for presence or absence of helminthes' ova and recorded. The intensity of infection was calculated as egg per gram. The remaining of each stool sample that was found negative by Kato-Katz method was processed by the formol-ether concentration method and examined by microscopy for confirmation or otherwise [33].

\section{Data analysis}

Data collected on each participant were independently double entered into the computer with Epi Info ${ }^{\mathrm{TM}} 7$. The data entered were cleaned, exported to and analysed with Statistical Package for Social Sciences (IBM SPSS Statistics 23). Participants were identified as anaemic using age specific cut-off points for haemoglobin concentrations. Thus, participants from 6 to 11 years old with haemoglobin concentrations $<115 \mathrm{~g} / 1$ and those 12 years old with haemoglobin concentrations $<120 \mathrm{~g} / 1$ were described as anaemic individuals as stated by WHO [34]. The cut-off value used to identify participants with vitamin A deficiency was serum retinol concentrations $<20 \mu \mathrm{g} / \mathrm{dl}(<0.70 \mu \mathrm{mol} / \mathrm{l})$. A participant was described as moderately and severely vitamin A deficient when serum retinol concentration was between 10 and $20 \mu \mathrm{g} / \mathrm{dl}(0.35$ and $0.70 \mu \mathrm{mol} / \mathrm{l})$, and less than $10 \mu \mathrm{g} / \mathrm{dl}(<0.35 \mu \mathrm{mol} / \mathrm{l})$ respectively. World Health Organization Anthro Software [35] was used to estimate z-scores for anthropometric indices. All measured variables were checked for normality. Haemoglobin, serum retinol, weight and height values were normally distributed. Their summary values are presented in the form of arithmetic means with standard deviations or otherwise as proportions. Mean serum vitamin A and 
haemoglobin concentrations and anthropometric indicators of participants at baseline and final were compared for any significant differences using paired t-tests. Significant differences between percentages or proportions (prevalence) of anaemia, VAD, and anthropometric indicators at baseline and final were determined by Chi-square test.

\section{Ethical approval}

Ethical approval was obtained to carry out this research study from the Institutional Review Board (IRB) of Noguchi Memorial Institute for Medical Research, College of Health Sciences, University of Ghana, Legon. The District Directorate of Education, the local Chief, Elders and the Head teacher of the selected school gave permission for the study to be executed. Written informed consent was obtained from the parents/guardians and oral consent from each pupil to participate in the study. 


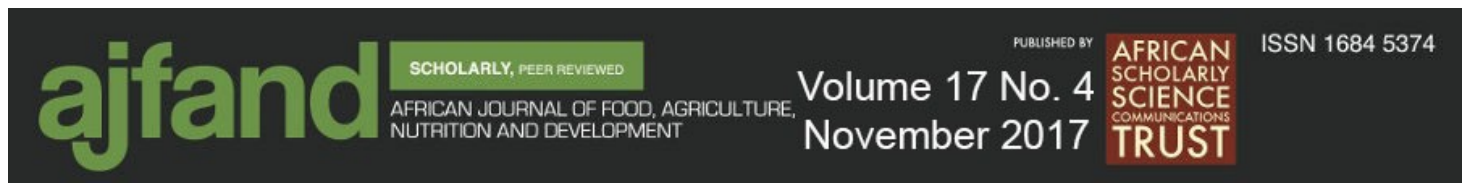

\section{RESULTS}

\section{Household characteristics}

Demographic characteristics of participating pupils and socio-economic information on their parents/guardians and households are presented in Table 1. The majority of parents or guardians of the participants $(68.3 \%)$ were farmers and many of these parents $(88 \%)$ earned monthly wages below the national minimum wage (GHф121.00; \$32.70). About $68 \%$ of participants' household members were registered for the National Health Insurance Scheme (NHIS) to attend any health facility recognized by the scheme.

\section{Dietary data}

Table 2 provides analysed data on the weekly consumption of foods in relation to the food groups available in Ghana. The results show that cereal (mostly maize), was the main food group consumed by the majority of the participants $-117(82.4 \%)$, at least seven times per week during the month proceeding the time of data collection. Also, a large proportion, $113(85.9 \%)$ of participants consumed vegetables (mostly green leafy vegetables) at least four times in a week. Dairy or dairy products, fat and oil consumption were not a common feature of the participants. Most participants- 140 (99\%) did not consume dairy or any dairy product on a weekly basis in the month before or during the data collection period.

\section{Biochemical and anthropometric indices}

Changes that occurred in some anthropometric and biochemical outcome variables are shown in Table 3 . The mean weight and height of the participants increased from baseline and final. There was a significant change in mean serum retinol concentration of study participants from baseline to final at $p=0.001$. The mean haemoglobin concentrations for all participants increased from baseline $(119.4 \pm 10.6 \mathrm{~g} / \mathrm{l})$ to final $(126.0 \pm 9.34 \mathrm{~g} / \mathrm{l})$ significantly, $p=0.001$. The prevalence of anaemia significantly decreased from $30.3 \%$ at baseline to $11.3 \%$ at final, $(\mathrm{p}=0.001)$. The prevalence of vitamin A deficiency decreased from $93.6 \%$ at baseline to $76.2 \%$ at final $(p=0.001)$.

Table 4 exclusively shows baseline and final results of participants who were with severe vitamin A deficiency at the start of the nutrition intervention study. The mean weight and height of this subset of the study participants at baseline were $26.2 \pm 8.79 \mathrm{~kg}$ and $126.2 \pm$ $17.5 \mathrm{~cm}$. Those at final were $28.1 \pm 9.70 \mathrm{~kg}$ and $131.2 \pm 16.2 \mathrm{~cm}$. There were significant changes from baseline to final for BMI-for-age $\mathrm{z}$ score $(0.485 \pm 0.059 ; \mathrm{p}=0.018)$, thinness $(19.0 \% ; p=0.008)$. The mean serum retinol concentration increased from $7.34 \mu \mathrm{g} / \mathrm{dl}$ at baseline to $17.7 \mu \mathrm{g} / \mathrm{dl}$ at the end of the study $(\mathrm{p}=0.0001)$. Before the initiation of the nutrition intervention, $40.9 \%(n=58)$ of the participants had severe VAD at baseline. However, at the end of the intervention study, only $15.5 \%(n=9)$ of the participants initially identified with severe VAD still had severe VAD (Table 4). At final $48.3 \%(\mathrm{n}=28)$ of the participants with severe VAD initially improved and their status changed to moderate VAD. Additionally, $36.2 \%(n=21)$ of the participants with severe VAD initially moved to normal serum retinol concentrations. Their mean haemoglobin concentrations increased from $118.8 \pm 11.4 \mathrm{~g} / \mathrm{l}$ at baseline to $126.4 \pm 9.9 \mathrm{~g} / \mathrm{l}$ at the end of the study, $\mathrm{p}=0.001$. The prevalence of anaemia among this severely deficient vitamin $\mathrm{A}$ 


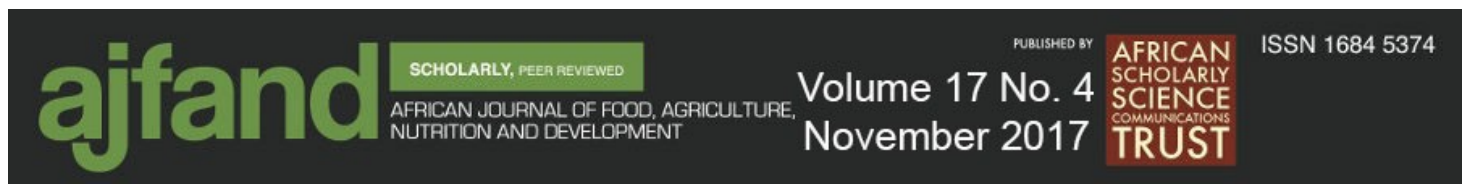

group of participants was $36.2 \%$ and $12.1 \%$ at the beginning and the end of the study, respectively. The reduction in prevalence of anaemia was significant $(p=0.001)$.

\section{Association between serum retinol and anthropometric indices}

The analysed data indicated an association between serum retinol concentration, nutritional status indicators, and household characteristics (Table 5). Height-for-age $\mathrm{z}$ score and Body Mass Index- for-age $\mathrm{z}$ score were significantly associated with serum retinol concentration ( $p=0.044$ and $p=0.03$, respectively).

\section{DISCUSSION}

\section{Level of vitamin-A deficiency and anaemia}

The baseline findings showed that the study participants were at risk for VAD, anaemia, and intense malarial infection. The present findings give support to previous research findings that school children are often affected by VAD, anaemia and parasitic infections globally $[5,6,7]$. The results showed that consumption of RPO bean- stew improved vitamin A status and also minimized the prevalence of anaemia among the study participants. At baseline, a large proportion of the participants had VAD to varying degrees and this is of public health interest. This could be linked to malaria infection and inadequate dietary intake of both preformed and pro-vitamin A-rich foods among the participants as revealed by the baseline data analyses.

A review on malaria and VAD in African children indicated that low serum retinol concentration was common among malaria-infected children [36]. However, the review could not conclude if this observation represented pre-existing VAD, the contribution of malaria to VAD, or an acute effect of malaria on retinol metabolism. The reduction in the level of malaria parasite density could not be substantiated as the result of the nutrition intervention carried out. There was a significant change in the mean vitamin A concentration of the participants at the end of the study which translated into an improved vitamin A status. The prevalence of VAD was minimized at the end of the intervention study. Earlier studies showed that RPO is a good source of pro- vitamin A (beta-carotene) and also an effective food ingredient for supporting vitamin A status of children and mothers in Sahel Africa [37,38].

The results obtained at baseline showed that the diets consumed by the participants were not diversified enough for them to meet their daily dietary requirements for vitamin A and other micronutrients (folate, vitamin $\mathrm{C}$, and iron) known to prevent or minimize nutritional anaemia. The participants frequently consumed cereal and grains that contained little or no pro-vitamin A carotenoids. The dietary pattern of the participants before the study indicated that their diets were poor in fruits, meat or meat products, poultry, dairy and dairy products. These are good sources of pro-vitamin A and preformed vitamin A, respectively. Leafy vegetables were their main source of vitamin A. These, taken in moderation alone without vegetable oil, would not provide enough readily bioavailable pro-vitamin A.

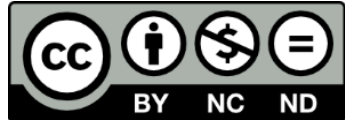


The intervention diet effectively improved the haemoglobin mean concentration of the participants. The change in mean haemoglobin concentration has been translated into a significant decline in prevalence of anaemia among the participants. Leafy vegetables are also known to be rich in non-heme iron but this is not highly bio-available for absorption due to anti-nutritional factors such as phytates, tannins and polyphenols. Non-heme iron absorption is enhanced by vitamin $\mathrm{C}$ largely provided by fruits, but consumption was minimal among the participants. Any improvement in haemoglobin concentrations might be linked to the constituents of the intervention diet.

The findings showed that majority of the participants with severe VAD at baseline had improved vitamin A status at the end of the study. The mean change in serum retinol concentration between baseline and the end of the study was a significant improvement, which translated into $48 \%$ of the participants having moderate VAD and $36 \%$ having normal vitamin A status. Previous intervention studies showed similar changes in vitamin A status in subjects that were vitamin A deficient at baseline [37, 38]. This is an indication that the intervention diet (RPO, a good source of beta-carotene) was effective in improving their vitamin A status. It also contained cowpea (commonly referred to as beans), which belongs to the leguminous food group known for high protein content and quality. The diet provided adequate protein for retinol binding protein synthesis.

The participants with severe VAD also had improved haemoglobin concentration that resulted in a significant decline in the prevalence of anaemia. The prevalence of malaria parasitaemia (of public health relevance) and other factors (not investigated in this study) could have contributed to the level of anaemia observed among the participants. The reduction in the prevalence of malaria parasitaemia was not significant and, therefore, unlikely to have contributed significantly to the increase in haemoglobin concentrations.

\section{STRENGTH AND LIMITATIONS}

The study was multipurpose in nature in that parasitological, dietary, anthropometric and biochemical data were captured simultaneously. It was limited to school children, and so it did not benefit other children in the study community who were not attending school. It was difficult to have a defined control group in the study setting. However, the baseline data collected served as a reference or control data for comparing the end of study data of the study participants.

\section{CONCLUSION}

The consumption of RPO bean-stew improved vitamin A status and minimized the level and prevalence of anaemia among the study participants. Red palm oil bean-stew has the potential to increase vitamin A and haemoglobin concentrations of consumers.

\section{Funding}

I acknowledge that the major funding for this research came from the Nestlé Foundation. 


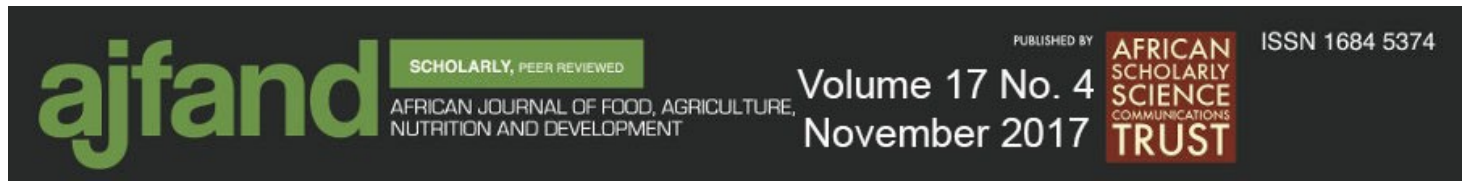

Table 1: Baseline and household characteristics of the study participants $(N=142)$

\begin{tabular}{lcc}
\hline Variable & Number of participants & Percentage (\%) \\
\hline Sex & & \\
\hline Boys & 77 & 54.2 \\
Girls & 65 & \\
Age (years) & & 71.8 \\
\hline $6-9$ & 102 & 28.2 \\
$10-12$ & 40 & \\
Parents'/guardians' occupation & & 68.3 \\
\hline Farming & 97 & 22.5 \\
Office work & 13 & \\
Other works & 32 & 14.1 \\
Parents'/guardians' marital status & & 85.9 \\
\hline Single & 20 & \\
Married & 122 & 88.0 \\
Monthly income of parents/guardians & & 12.0 \\
\hline$<$ minimum wage (GH $\notin 121)$ & 125 & \\
$\geq$ minimum wage (GH $\not 121)$ & 17 & 67.6 \\
National Health Insurance (Household Level) & & 32.4 \\
\hline Registered & 96 & \\
Unregistered & 46 & \\
\hline
\end{tabular}




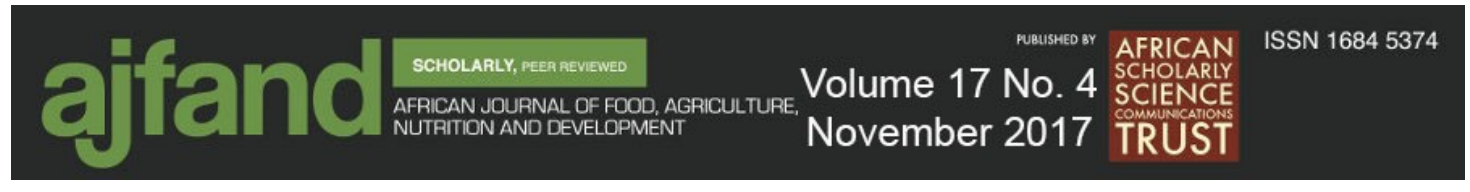

Table 2: Weekly food consumption pattern of study participants $(\mathrm{N}=142)$

\begin{tabular}{lcccc}
\hline Food group & \multicolumn{4}{c}{ Consumption pattern } \\
\cline { 2 - 5 } & $\begin{array}{c}\text { Never } \\
\%(\mathrm{n})\end{array}$ & $\begin{array}{c}1-3 \text { times } \\
\%(\mathrm{n})\end{array}$ & $\begin{array}{c}4-6 \text { times } \\
\%(\mathrm{n})\end{array}$ & $\begin{array}{c}\geq 7 \text { times } \\
\%(\mathrm{n})\end{array}$ \\
\hline Cereals/grains & - & - & $17.6(25)$ & $82.4(117)$ \\
Roots/tubers & $7.7(11)$ & $35.2(50)$ & $33.8(48)$ & $22.5(32)$ \\
Legumes \& nuts & $31.0(44)$ & $53.5(76)$ & $13.4(19)$ & $2.1(30)$ \\
Fruits & $47.9(68)$ & $38.0(54)$ & $11.3(16)$ & $2.8(4)$ \\
Vegetables & $5.6(8)$ & $20.4(29)$ & $47.9(68)$ & $31.7(45)$ \\
Poultry/meat/fish & & $20.4(29)$ & $47.9(68)$ & $31.7(45)$ \\
Fats \& oils & - & $39.4(56)$ & $16.9(24)$ & $0.7(1)$ \\
Dairy/dairy products & $98.6(140)$ & $1.4(2)$ & - & - \\
\hline
\end{tabular}

* Refers mostly to consumption of fish with negligible amount of bush meat consumption 


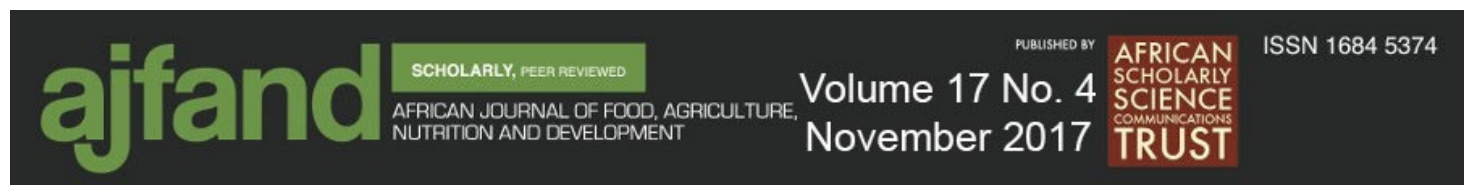

Table 3: Anthropometric and biochemical outcome variables of the study participants at baseline and end-line $(n=142)$

\begin{tabular}{|c|c|c|c|c|}
\hline Variable/index & $\begin{array}{l}\text { Baseline } \\
\text { Mean } \pm \text { SD }\end{array}$ & $\begin{array}{l}\text { End-line } \\
\text { Mean } \pm \text { SD }\end{array}$ & Change & $\mathrm{P}^{\mathrm{x}}$ \\
\hline Weight (kg) & $26.9 \pm 7.95$ & $28.6 \pm 8.6$ & $1.71 \pm 0.65$ & 0.001 \\
\hline Height (cm) & $128.5 \pm 15.3$ & $133.2 \pm 14.3$ & $4.69 \pm 1.08$ & 0.001 \\
\hline $\begin{array}{l}\text { Weight-for-age-z score } \\
\text { (WAZ) }\end{array}$ & $-1.05 \pm 0.82$ & $-1.04 \pm 0.94$ & $-0.01 \pm 0.12$ & 0.941 \\
\hline $\begin{array}{l}\text { Height-for-age-z score } \\
\text { (HAZ) }\end{array}$ & $-1.11 \pm 1.2$ & $-0.53 \pm 2.93$ & $0.58 \pm 1.73$ & 0.027 \\
\hline BMI-for-age-z score (BAZ) & $-0.59 \pm 0.92$ & $-0.74 \pm 0.98$ & $0.15 \pm 0.06$ & 0.054 \\
\hline $\begin{array}{l}\text { Underweight (WAZ <- } \\
\text { 2SD), }(\%)\end{array}$ & 10.1 & 12.5 & 2.4 & 0.653 \\
\hline Stunting (HAZ <-2SD), (\%) & 24.0 & 20.0 & 4.0 & 0.145 \\
\hline Thinness (BAZ <-2SD), (\%) & 8.0 & 9.0 & 1.0 & 0.824 \\
\hline Serum retinol conc. $(\mu \mathrm{g} / \mathrm{dl})$ & $12.11 \pm 6.61$ & $16.16 \pm 6.41$ & $4.05 \pm 0.02$ & 0.001 \\
\hline Haemoglobin conc. $(\mathrm{g} / \mathrm{l})$ & $119.4 \pm 10.6$ & $126.0 \pm 9.34$ & $6.61 \pm 1.29$ & 0.001 \\
\hline Vitamin A deficiency ${ }^{3}(\%)$ & 93.6 & 76.2 & 17.4 & 0.001 \\
\hline Level of anaemia ${ }^{4}(\%)$ & 30.3 & 11.3 & 19.0 & 0.001 \\
\hline Malaria parasitaemia density & $2923 \pm 5667$ & $865.2 \pm 1312$ & $2058 \pm 4355$ & 0.008 \\
\hline Malaria parasitaemia (\%) & 67.6 & 62.7 & 4.9 & 0.093 \\
\hline
\end{tabular}

Abbreviations: BMI, Body Mass Index; SD, standard deviation

${ }^{1}$ Values are means \pm SD otherwise percentages $(\%)$

${ }^{\mathrm{x}}$ Paired $\mathrm{t}$ test or Chi-squared test, with significant limit set at $\mathrm{p}<0.05$

${ }^{3}$ Serum retinol concentration $<20 \mu \mathrm{g} / \mathrm{dl}$

${ }^{4}$ Anaemia: haemoglobin concentration $<115 \mathrm{~g} / 1$ in children less than 12 years and haemoglobin concentration $<120 \mathrm{~g} / 1$ in children aged 12 years 


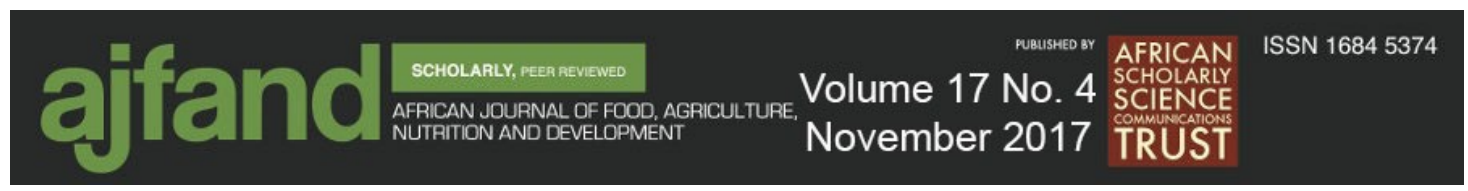

Table4: Anthropometric and biochemical variables of study participants with severe vitamin A deficiency before initiation of the nutrition intervention feeding

\begin{tabular}{|c|c|c|c|c|}
\hline \multirow[t]{2}{*}{ Variable } & \multicolumn{4}{|c|}{ Study participants } \\
\hline & Baseline $(\mathrm{n}=58)$ & End-line $(\mathrm{n}=58)$ & Change & $\mathrm{P}^{\mathrm{x}}$ \\
\hline Weight (kg) & $26.24 \pm 8.79$ & $28.12 \pm 9.70$ & $1.88 \pm 1.44$ & 0.001 \\
\hline Height (cm) & $126.16 \pm 17.45$ & $131.17 \pm 16.22$ & $5.01 \pm 3.83$ & 0.001 \\
\hline $\begin{array}{l}\text { Height-for-age z score } \\
\text { (HAZ) }\end{array}$ & $-1.110 \pm 1.153$ & $-0.915 \pm 1.148$ & $-0.195 \pm 0.010$ & 0.240 \\
\hline BMI-for-age z score (BAZ) & $-1.120 \pm 1.217$ & $-0.635 \pm 1.276$ & $0.485 \pm 0.059$ & 0.018 \\
\hline Stunting (HAZ<-2SD) & 25.7 & 22.4 & 3.3 & 0.593 \\
\hline Thinness (BAZ<-2SD) & 27.6 & 8.6 & 19 & 0.008 \\
\hline Retinol conc. $(\mu \mathrm{g} / \mathrm{dl})$ & $7.34 \pm 1.53$ & $17.72 \pm 7.04$ & $10.37 \pm 5.53$ & 0.001 \\
\hline $\begin{array}{l}\text { Severe vitamin A } \\
\text { deficiency }^{3 a}\end{array}$ & 100 & 15.5 & 84.5 & 0.001 \\
\hline $\begin{array}{l}\text { Moderate vitamin A } \\
\text { deficiency }^{\text {b }}\end{array}$ & - & 48.3 & - & - \\
\hline Normal vitamin $\mathrm{A}_{\text {level }}{ }^{3 \mathrm{c}}$ & - & 36.2 & - & - \\
\hline Haemoglobin conc. (g/l) & $118.83 \pm 11.44$ & $126.36 \pm 9.92$ & $7.53 \pm 2.52$ & 0.001 \\
\hline Anaemia $^{4}$ & 36.2 & 12.1 & 24.1 & 0.001 \\
\hline
\end{tabular}

Abbreviations: BMI, Body Mass Index; SD, standard deviation

${ }^{1}$ Values are means \pm SD otherwise percentages (\%)

${ }^{x}$ Paired $t$ test or Chi-squared test

${ }^{3 \mathrm{a}}$ Severe vitamin A deficiency classified as retinol concentration $\mathrm{X}<10 \mu \mathrm{g} / \mathrm{dl}(<0.35 \mu \mathrm{mol} / \mathrm{l})$

${ }^{3 b}$ Moderate vitamin A deficiency classified as retinol concentration $X \geq 10 X<20 \mu \mathrm{g} / \mathrm{dl}$ (or $X \geq 0.35 X$ $<0.70 \mu \mathrm{mol} / \mathrm{l})$

${ }^{3 \mathrm{c}}$ Normal vitamin A deficiency classified as retinol concentration $\mathrm{X} \geq 20 \mu \mathrm{g} / \mathrm{dl}$ ( or $\mathrm{X}>0.70 \mu \mathrm{mol} / \mathrm{l}$ )

${ }^{4}$ Anaemia: haemoglobin concentration $\mathrm{X}<115 \mathrm{~g} / 1$ in children less than 12 years and haemoglobin concentration $X<120 \mathrm{~g} / 1$ in children aged 12 years 


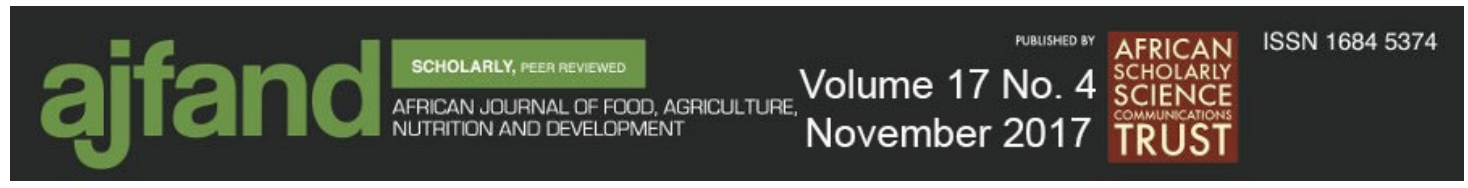

Table 5: Relationships between serum retinol concentration, nutritional status indicators and household characteristics of study participants

\begin{tabular}{lccc}
\hline Characteristic or indicator & Regression coefficient & R-square & $\mathrm{P}^{\mathrm{x}}$ \\
\hline Education of parent or guardian & 1.041 & 0.010 & 0.341 \\
Monthly income of parent or guardian & 1.002 & 0.011 & 0.213 \\
National health insurance (NHI) status & 1.114 & 0.022 & 0.082 \\
Family size & 0.995 & 0.001 & 0.697 \\
Height-for-age z score (HAZ) & 1.124 & 0.173 & 0.044 \\
Body Mass Index-for-age z score & 1.215 & 0.184 & 0.03 \\
\hline
\end{tabular}

${ }^{\mathrm{x}}$ Values were derived by univariate linear regression or by multi linear regression model 


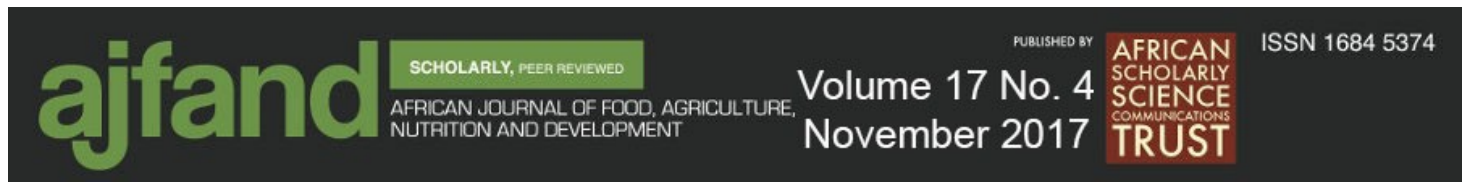

\section{REFERENCES}

1. Jones KM, Specio SE, Shrestha P, Brown HK and LH Allen Nutritional knowledge and practices and consumption of vitamin A-rich plants by rural Nepali participants and nonparticipants in a kitchen-garden programme. Food Nutr. Bull., 2005; 26:198-208.

2. Arlappa N, Laxmaiah A, Balakrishna N, Harikumar R and GNV Brahmam Clinical and sub-clinical vitamin A deficiency among rural pre- school children of Maharashtra, India. Ann. Hum. Biol., 2008; 35(6): 606-614.

3. Semba RD and MW Bloem The anaemia of vitamin A deficiency: epidemiology and pathogenesis. Eur. J. Clin.Nutr., 2002; 56:271-281.

4. Gamble MV, Palafox NA, Dancheck B, Ricks MO, Briand K and RD Semba Relationship of vitamin A deficiency, iron deficiency and inflammation to anemia among preschool children in the Republic of the Marshall Islands. Eur. J.Clin.Nutr. 2004; 58:1396-1401.

5. Singh V and KP West Vitamin A deficiency and xerophthalmia among schoolaged children in Southeastern Asia. Eur.J.Clin.Nutr, 2004; 58(10):1342-1349.

6. Hall A, Bobrow E, Brooker S, Jukes M, Nokes K, Lambo J, Guyatt H, Bundy D, Adjei S, Wen ST, Subagio H, Rafiluddin MZ, Miguel T, Moulin S, de Graft Johnson J, Mukaka M, Roschnik N, Sacko M, Zacher A, Mahumane B, Kihamia C, Mwanri L, Tatala S, Lwambo N, Siza J, Khanh LN, Khoi HH and ND Toan Anaemia in school children in eight countries in Africa and Asia. Public Health Nutr. 2001;4(3):749-756.

7. Brooker S, Clements AC, Hotez PJ, Hay SI, Tatem AJ, Bundy DA andRW Snow The co-distribution of Plasmodium falciparum and hookworm among African school children. Malar. J., 2006; 5:99.

8. Ministry of Health Vitamin A Prevalence Survey (MOHVAPS). In: Amoaful EF(ed.). Planning a national food-based strategy for sustainable control of vitamin A deficiency in Ghana: steps toward transition from supplementation. 1997.

9. Egbi G Prevalence of vitamin A, zinc, iodine deficiency and anemia among 210 year- old Ghanaian children. AJFAND, 2012;12(2):5946-5958.

10. Abizari AR, Moretti D, Zimmermann MB, Armar-Klemesu M and ID Brouwer Whole cowpea meal fortified with NaFeEDTA reduces iron deficiency among Ghanaian school children in malaria endemic area. J. Nutr., 2012; 142: 1836-1842.

11. Egbi G, Steiner-Asiedu M, Saalia FK, Ayi I, Ofosu W, Setorglo J, Klobodu

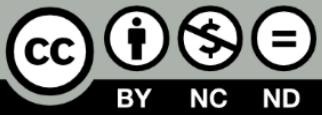


SS and M Armar-Klemesu Anaemia among school children older than five years in the Volta Region of Ghana. Pan Afr. Med. J., 2014; 17(Supp 1):10.

12. Osei-Boadi K, Lartey A, Marquis G and E Colecraft Dietary intakes and iron status of vegetarian and non-vegetarian children in selected communities in Accra and CapeCoast, Ghana. AJFAND, 2012; 12(1):5822-5842.

13. Srivastava A, Mahmood SE, Srivastava PM, Shrotriya VP andB Kumar Nutritional status of school-age children-a scenario of urban slums in India. Archives of Public Health, 2012; 70:8.

14. Bryce J, Coitinho D, Darnton-Hill I, Pelletier D andP Pinstrup-Andersen Maternal and child under nutrition: effective action at national level. Lancet, 2008; 371:510-526.

15. Sachs JD Macroeconomics and health: investing in health for human development. Geneva: World Health Organization, 2001.

16. Sen A Inequality reexamined. Boston MA: Russell Sage Foundation Books, Harvard University Press. 1995; ISBN13: 978-0-674-45255-8.

17. Lau HLN, Choo YM, Ma ANandCH Chuah Selective extraction of palm carotene and vitamin $\mathrm{E}$ from fresh palm-pressed mesocarp (Elaeis guineensis) using supercritical CO2. J. Food Eng., 2008; 84:289-296.

18. Scrimshaw NS Nutritional potential of red palm oil for combating vitamin A deficiency. Food Nutr. Bull., 2000;21:195-201.

19. Malaysian Palm Oil Council (MPOC) How much RPO to supply the RDA for vitamin A? 2006 http://www.mpoc.org.pk/. Accessed 20 th November 2011.

20. Ong AS and SH Goh Palm oil: a healthful and cost-effective dietary component. Food Nutr. Bull., 2002;23(1):11-22.

21. Phillips RD, McWatters KH, Chinnan MS, Hung YC, Beuchat LR, SefaDedeh S, Sakyi-Dawson E, Ngoddy P, Nnanyelugo D, Enwere J, Komey NS, Liu KS, Mensa-Wilmot Y, Nnanna IK, Okeke C, Prinyawiwatkul W and FK Saalia Utilization of cowpea for human food. Field Crops Res., 2003; 82:193213.

22. Preet K and D Punia Proximate composition, phytic acid, polyphenols and digestibility (in-vitro) of four brown cowpea varieties. Int. J Food Sci.Nutr, 2000; 51:189-193.

23. Madode YE, Houssou PA, Linnemann AR, Hounhouigan DJ, Nout MJR and MAJS van Boekel Preparation, consumption and nutritional composition of West African cowpea dishes. Ecol Food Nutr, 2011;50:115-136. 
24. Quaye W, Adofo $\mathrm{K}$, Madode YE and AR Abari Exploratory and multidisciplinary survey of cowpea network in Tolon-Kumbungu district of Ghana: A food sovereignty perspective. AJAR, 2009; 4:311-320.

25. Onigbinde AO andIO Akinyele Oligosaccharide content of 20 varieties of cowpeas (Vigna unguiculata) in Nigeria. J. Food Sci., 1983;48:1250-1251.

26. Oluwatosin OB Genetic and environmental variation for seed yield, protein, lipid and amino acid composition in cowpea (Vigna unguiculataL. Walp). J. Sci. Food Agri., 1997; 74:107-116.

27. Frota KMG, MendonçaS, Saldiva PHN, Cruz RJ and JAG Arêas CholesterolLowering Properties of Whole Cowpea Seed and its Protein Isolates in Hamsters. J. Food Sci., 2008; 73:9.

28. Official Methods of Analysis of the Association of Official Analytical Chemists (AOAC) Association of Analytical Chemists, 1995. Washington, DC. U. S. A.

29. Rodriguez-Amaya DB and M Kimura HarvestPlus Handbook for Carotenoid Analysis. HarvetPlus Technical Monograph Series 2, 2004. 37-50. Washington DC and California.

30. Kimura M and DB Rodriguez-Amaya A Scheme for obtaining standards and HPLC quantification of leafy vegetable carotenoids. Food Chemistry, 2002; 78:389-398.

31. World Health Organization (WHO). Growth reference data for children from 5 to 19 years. Geneva 2007. (http://www.who.int/growthref/en/) Accessed $6^{\text {th }}$ January 2010.

32. Noguchi Memorial Institute for Medical Research (NMIMR) Procedure for analysing serum and breast-milk retinol. Department of Nutrition, NMIMR, Legon, Ghana 1997.

33. Cheesbrough M District Laboratory Practice in Tropical Countries Part1. Cambridge. Cambridge UniversityPress, 1998.

34. World Health Organization (WHO). Iron deficiency anaemia: Assessment, prevention and control: A guide for programme managers. Geneva: World Health Organization, 2001.

35. World Health Organization (WHO). Anthro for personal computers, version 3.2.2, 2010: software for assessing growth and development of the world's 


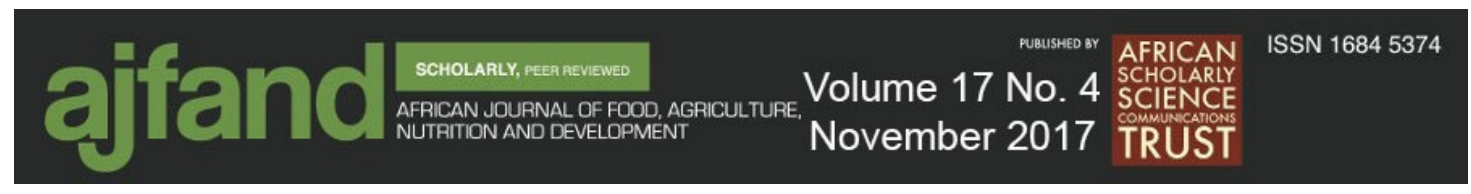

children. Geneva: WHO 2010. http://www.who.int/childgrowth/software/en/ Accessed $4^{\text {th }}$ June 2011.

36. SanJoaquin MA and ME Molyneux Malaria and vitamin A deficiency in African children: a vicious circle? Malar. J., 2009; 8:134, doi: 10.1186/14752875-8-134.

37. Van Stuijvenberg ME, Dhansay MA, Lombad CJ, Faber M and AJS Benadé The effect of a biscuit with red palm oil as a source of beta-carotene on the vitamin A status of primary school children: a comparison with beta- carotene from a synthetic source in a randomized controlled trial. Eur J. Clin. Nutr. 2001; 55:657662.

38. Zeba AN, Prével YM, Somé IT and HF Delisle The positive impact of red palm oil in school meals on vitamin A status: study in Burkina Faso. Nutr. J. 2006; 5:17 doi: 10.1186/1495-2891-5-17. 